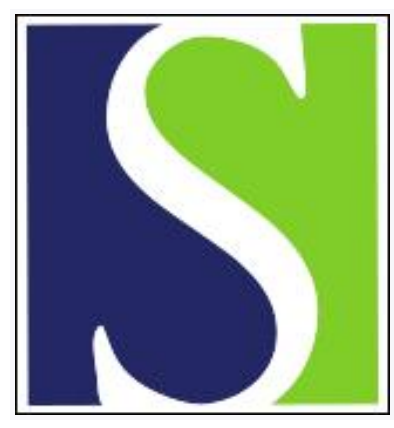

Scand J Work Environ Health 2014;40(1):104

https://doi.org/10.5271/sjweh.3410

Published online: 19 Dec 2013, Issue date: 01 Jan 2014

\title{
Current topics in occupational epidemiology
}

by Kristensen $P$

Key terms: book review; occupational epidemiology

\section{(c) (i)}


Current Topics in Occupational Epidemiology by Katherine Venables (Editor). Oxford: Oxford University Press, 2013. 288 pages. ISBN: 978-0-19-968390-1. Available as eBook (Price: £34.99. http://ukcatalogue.oup.com/ product/9780199683901.do)

This is not a textbook of occupational epidemiology, and there is no attempt to provide a comprehensive overview of the field. So why read this book? I recommend it because it includes an interesting collection of new topics in addition to "old" ones viewed from a new perspective. Some of the 19 chapters invite us to reconsider established truths and ask basic questions.

Editor Katherine Venables knows the field of occupational epidemiology better than most. She has collected an interesting selection of topics contributed by 49 authors. The book is divided into seven parts, covering "new" occupational diseases, emerging population groups of interest, as well as fresh issues, approaches, methods, and concepts in the field. Although there is no room for a comprehensive overview in this book review, I hereby present some examples.

Heederik and cowriters have studied microbial resistance in livestock farming. Methicillin-resistant Staphylococcus aureus (MRSA) is an example of drug-resistant pathogens of global concern. In a very interesting chapter, the authors show this is a major issue of concern not only for public but also occupational health. They demonstrate that occupational health and hygiene principles will not only apply to the prevention of MRSA infection among livestock farmers and their families but will also be of value in reducing the risk in the general population.

Pearce and Corbin put forth the provocative question "Why do occupational epidemiologists act as Bayesians in Introduction and Discussion but as frequentists in Methods and Results in article writing?" They advocate the Bayesian approach (authors often already are without realizing it) which can be achieved by routine adjustment for multiple comparisons and careful conduct of sensitivity analyses, enabling us to assess bias in a quantitative manner. Pearce and Corbin predict that analytical tools for these purposes will be increasingly available in standard statistical packages; this will enable us to address the elephant in the room more clearly and assess problems of multiple comparisons and bias in a quantitative manner.

Another interesting method chapter addresses systematic reviews in the field of occupational safety and health (Verbeek and Ijaz). One important take-home message is that publication bias is probably a more important issue for observational than intervention studies.
Part 2, "Studying New Populations", covers three groups that are subject to increasing focus in developed countries: deployed military personnel (will they end up "bad, sad, or mad"?), migrant workers, and older employees. The chapter addressing epidemiology and migrant workers (Ronda and coworkers) states that human migration has always been an important global phenomenon. Yet epidemiologic research is primarily framed as a matter for the recipient country and the occupational health problems mentioned in this chapter are restricted to those of the "here and now": fatal and non-fatal occupational injuries, presenteeism, and self-reported health. My thought when reading this chapter was that if work life has become globalized, why can't the epidemiology of work migration be globalized as well? In one sense, the epidemiology of migration ought to strive for a life course perspective. Some of the well-known selection issues of migration that create method problems for the epidemiologist ("brain drain") would be elucidated best by comparing with the population of origin. Further, migrant workers are probably at increased risk of chronic diseases with long latency time (eg, COPD and occupational cancer). Those who stay can certainly be studied in the recipient country. However, health problems among workers who return to their native country, either to die ("salmon bias") or retire, will be easier to follow up in the country of origin.

Part 3 also extends beyond traditional occupational epidemiology by closing the gap to social epidemiology. The reader will find interesting chapters covering issues such as work participation, unemployment, sickness absence, return to work, and permanent disability. Social and health-related adversity from long-term unemployment among young people has been a particular concern. The Swedish experience on this important topic is shared by researchers from Uppsala University.

This selection of contemporary topics can be read by all epidemiologists and experts in the field of occupational medicine and hygiene. The topics are not only mindful in their own right, but could be helpful in promoting our field among the broader public and policy-makers. Indeed, the publisher claims the book will be essential reading not only for epidemiologists, statisticians, and exposure assessment scientists, but also for policy-makers. Even if I do not fully agree with this, some chapters could be of interest to policy-makers without professional knowledge in the specific field of occupational epidemiology.

\section{Petter Kristensen \\ Dept Occupational Medicine and Epidemiology \\ National Institute of Occupational Health \\ Oslo, Norway. [e-mail: pkr@stami.no]}

